\title{
Does Tabletop Exercise Enhance Knowledge and Attitude in Preparing Disaster Drills?
}

\author{
Cut Husna ${ }^{1}$, Hajjul Kamil ${ }^{1}$, Mustanir Yahya ${ }^{2}$, Teuku Tahlil ${ }^{1,}$ Darmawati Darmawati ${ }^{1}$ \\ ${ }^{1}$ Faculty of Nursing, Universitas Syiah Kuala, Banda Aceh, Indonesia \\ ${ }^{2}$ Faculty of Sciences, Universitas Syiah Kuala, Banda Aceh, Indonesia \\ Corresponding Author: Cut Husna (cuthusna@unsyiah.ac.id)
}

Accepted: 17 August 2020

\begin{abstract}
Background: Tabletop Exercise (TTE) is a specific learning method through a simulation designed to test the competency and the ability of a group to respond to disasters. Using the map of disaster events is considered effective to prepare disaster drills rather than other methods. TTE method has been carried out annually to train the students, however, limited studies reported the effect of this method.

Purpose: The study aimed to evaluate the effect of TTE on enhancing nursing students' knowledge and attitude in a disaster drill.

Methods: This study was conducted with one-group pre and post-test of a quasi-experimental design. The total samples were 80 nursing students of the fourth year who undertook the disaster nursing course. The intervention of the study was started using the scenario of an earthquake disaster simulation using TTE media divided into four groups. The instruments consisted of two questionnaires: Students' Knowledge on Tabletop Exercise (SKTE), and Students' Attitude on Tabletop Exercise (SATE) which were tested for their validity and reliability. The data were analyzed using a dependent paired t-test.

Results: The study showed that the tabletop exercise had a positive effect in enhancing the knowledge $(p=0.001)$ and the attitude of nursing students in disaster drills $(p=0.001)(d f=79)$.

Conclusion: TTE Intervention was an effective direct learning method to improve students' competencies in disaster response. TTE might be considered as a learning method in improving students' competencies in preparing disaster drills.
\end{abstract}

Keywords: Attitude; disaster; knowledge; nursing student, tabletop exercise

How to Cite: Husna, C., Kamil, H., Yahya, M., Tahlil, T., \& Darmawati, D. (2020). Does tabletop exercise enhance knowledge and attitude in preparing disaster drills?. Nurse Media Journal of Nursing, 10(2), 182-190. doi:10.14710/nmjn.v10i2. 29117

Permalink/DOI: https://doi.org/10.14710/nmjn.v10i2.29117

\section{BACKGROUND}

Geographically, Indonesia is located in a series of "rings of fire" that stretch along with the Pacific plate which is the most active tectonic plate in the world. This zone contributes about $90 \%$ of earthquake events and almost all of them are major earthquakes in the world (National Board for Disaster Management, 2014). Because of this condition, Indonesia has a high risk of recurrent disasters and vulnerability to disasters. The disaster may be caused by either natural or man-made human factors, resulting in devastations such as human impacts: physical, 
psychological, psychosocial and spiritual problems; environmental damage; and loss of property (Husna, Kamil, Yahya, \& Tahlil, 2020). The impacts also destroy the social life of the community, especially on the physical, emotional, and psychological health (Althobaity, Plummer, \& Williams, 2017; Park \& Kim, 2017). The occurrence of natural disasters, social conflict, and warfare can significantly cause economic and human life losses. These kinds of disasters are certainly very harmful to society.

However, although various disasters occurred, the disaster management is still having many challenges (Husna, Hatthakit, \& Chaowalit, 2011b; Husna, Tahlil, Kamil, \& Hayaturrahmi, 2018; Yi, George, Paul, \& Lin, 2010). Disaster preparedness should be a priority, especially in the disaster high-risk area, including nursing schools. The training and drill as an effective learning method improve the knowledge and ability of disaster preparedness (Alim, Kawabata, \& Nakazawa, 2015). A tabletop exercise is a preparedness exercise to formulate an emergency condition during a disaster by the simulated action to respond to disasters or emergency casualties. The groups or teams learn together in a particular emergency situation and then arrange the emergency plan during the disaster. TTE attempts to clarify the roles and responsibilities of a disaster team and to examine the capability of the mitigation and the preparedness of the drill team. The output of this exercise is an action plan for an emergency situation, where the respective team is given a role (Police University Wisconsin, 2012).

TTE allows the participants to conduct and show in a scenario-based exercise, mitigating and responding to the disaster. TTE provides the team with understanding and experience of specific contingency action plans in disaster simulations. In addition, TTE may train and improve the personnel's capabilities with respect to roles and responsibilities in a disaster drill, and understanding of disaster management. TTE also facilitates an open discussion between the team about an emergency or disaster scenario in a stress-free environment (Watson, Waddell, \& McCourt, inpress). The most important thing in disaster preparedness is to prepare the best disaster team through TTE to simulate the experience and the skills in disaster management, so that they could perform effectively in managing chaotic situations during disasters. Effective periodic disaster simulations can assist teamwork and communication to improve prehospital competencies in carrying out effective emergency procedures (Leikin, Aitchison, Pettineo, Kharasch, \& Wang, 2011). Moreover, hands-on learning or a drill has a positive impact on the confidence and the knowledge following the instruction in emergency settings or disasters (Bulloch, Pharm, Pinner, Pharm, \& Eure, 2013). The disaster drill could lead to improve the disaster response competencies (Araz \& Jehn, 2013; Nadian, Nik, Sipon, $\&$ Rahim, 2015), and a significant increase in the level of confidence in providing core public health services during the disaster drill (Su et al., 2013).

Because of the vulnerability and the increasing frequency of disasters occurring in the $21^{\text {st }}$ century, it is necessary for the nursing institutions to enhance students' competencies in preparing for disaster. Nursing education must reflect the attainment of nurses' competencies in improving the quality of services, especially in disaster, through the use of various teaching methods (Chee, 2014). Incorporating TTE into the teaching methods is an effort to ensure an adequate response to the disaster. Collaborative learning is obtained through TTE for disaster preparedness or drills (Alfred et al., 2015). Additionally, the training and disaster drills enhance the knowledge and the ability of the nursing students to be well prepared in responding to the disaster (Alim et al., 2015). 
TTE is a learning method that is easy and cost-effective. A study mentioned that TTE had a cost-efficient means to train and test public health response to disasters (Sandström, Eriksson, Norlander, Thorstensson, \& Cassel, 2014). The advantages of TTE from other disaster simulation methods are cost-effective, easy, applicable, and helping teamwork in accordance with their roles and functions effectively. Although several studies explain a positive effect in increasing knowledge from TTE exercises, limited studies reported a positive effect of TTE on changing student attitudes in preparation for disaster drills. This research study tries to address the currently existing gaps in the literature.

\section{PURPOSE}

This study aimed to evaluate the effect of TTE on enhancing nursing students' knowledge and attitude in a disaster drill.

\section{METHODS}

\section{Research design and setting}

This quasi-experimental study was conducted using one group pre and post-test design in January 2019 in a faculty of nursing of a public university in Banda Aceh, Indonesia.

\section{Participants and sampling}

The total sampling was conducted to recruit 80 nursing students as respondents. Respondents were chosen by purposeful selection according to the following inclusion criteria: fourth-year students, aged 19 to 23 years, and currently taking a disaster nursing course. The exclusion criteria were the students who have been involved in the TTE simulation before.

\section{Measurements}

The research instruments included two questionnaires. The first questionnaire was the Students' Knowledge on Tabletop Exercise (SKTE), consisting of 23 questions in the dichotomy scale, which included questions about roles, functions, tasks, and responsibilities of each drill team, and constructed based on the previously reported studies. The second questionnaire was the Students' Attitude on Tabletop Exercise (SATE) that consisted of 10 items on Likert scales with 4-point scales "disagree", "uncertain", "agree" and "strongly agree". The validity test was conducted with three experts in order to fix the contents. The feedbacks were rearranged in the right order with several modifications in the contents. Both questionnaires had been tested for their reliability to 20 nursing students with the values of 0.873 and 0.904 , respectively. The pre-test of the study was measured before TTE activities, and the post-test was evaluated in a week after the TTE intervention.

\section{Intervention}

The intervention of the study was started by using the scenario of an earthquake disaster simulation using TTE media for 80 nursing students, that were divided into four groups. TTE lasted for 90 minutes in the nursing laboratory. The students had been given their respective roles to carry out TTE. To avoid the bias of the study, the students were not provided any materials about TTE before doing the pretest. Prior to TTE simulations, briefings about the roles and functions of team members were conducted. TTE scenario was carried out by determining the roles of each student using the TTE media provided. TTE study was conducted in the second week of full-day learning in the laboratory phase. The students were given roles according to their duties and responsibilities, as follows: (1) incident commander, (2) search 
and rescue team, (3) triage team, (4) first aid team, (5) the ambulance team, (6) police and fireman team, (7) disaster victim identification team, and (8) field hospital team.

\section{Data analysis}

The pre-test and post-test data were normally distributed. A dependent paired t-test was used to analyze the differences of respective results. The comparison of the average scores included the knowledge and attitudes of nursing students in TTE.

\section{Ethical considerations}

This study had been approved by the Research Ethics Committee of the Faculty of Nursing, Universitas Syiah Kuala Banda Aceh, with the number 113006101218 on December 26, 2018. The permission from the faculty where this research was carried out had also been obtained. Approved written consents were collected from the students prior to the pre-test. Respondents understood the research objectives, risks, and benefits, and had the right to refuse. In addition, the confidentiality of the respondents was guaranteed.

\section{RESULTS}

\section{Characteristics of respondents}

Table 1 showed that the mean age of the respondents was $20.7 \pm 0.59$ while the majority of the respondents were females $(92.5 \%)$ and had attended the disaster drill before $(95 \%)$.

Table 1. Demographic characteristics of respondents $(n=80)$

\begin{tabular}{|c|c|c|c|c|c|}
\hline Demographic data & Mean \pm SD & Min & Max & $F$ & $\%$ \\
\hline Age (year) & $20.7 \pm 0.59$ & 19 & 22 & & \\
\hline \multicolumn{6}{|l|}{ Sex } \\
\hline Female & & & & 74 & 92.5 \\
\hline Male & & & & 6 & 7.5 \\
\hline \multicolumn{6}{|c|}{ Had attended in the disaster drill } \\
\hline Yes & & & & 76 & 95 \\
\hline No & & & & 4 & 5 \\
\hline
\end{tabular}

\section{Differences in knowledge and attitude of nursing students}

There was a significant increase in the mean scores of knowledge $(p=0.001)$ and attitude $(p=0.001)$ of the nursing students after TTE. However, the students' attitudes had a higher increase compared to the students' knowledge (Table 2).

Table 2. The students' knowledge and attitude in preparing disaster drills $(n=80)$

\begin{tabular}{lccrc}
\hline & Pre-test & Post-test & \multirow{2}{*}{$t$} & \multirow{2}{*}{$p$} \\
\cline { 2 - 3 } & $M(S D)$ & $M(S D)$ & & \\
\hline Knowledge & $40.29(4.02)$ & $42.55(3.39)$ & -4.05 & 0.001 \\
\hline Attitude & $31.53(3.71)$ & $35.05(3.35)$ & -6.23 & 0.001 \\
\hline
\end{tabular}

Note: $d f=79$, $\mathrm{t}=$ sample t-test

\section{DISCUSSION}

The result of the study showed that the TTE intervention affected positively on the nursing students' knowledge and attitudes in disaster drill preparation. This result is supported by 
Watson et al., (inpress) pointing out that tabletop exercise increases understanding of disaster management, roles in a disaster, and identifies strengths and weaknesses of participants who manage the disaster. TTE activities, as a pre-drill preparation, may provide baseline knowledge for the students when conducting disaster management. The advantage of TTE deals with teamwork effectiveness, where the stressful working environment has to be avoided. Tabletop drilling had improved the performance and provided more effective learning opportunities than the field training in disaster or emergency response. Several obstacles in disaster drill training such as communication problems, coordination, responsibilities, and mitigation priorities can be overcome by TTE.

From the result of the study, it could be explained that the understanding of the TTE simulation has changed nursing students' mindset and attitudes to be more prepared and responsive in facing disasters. Compared to the other methods, TTE is superior to support the nursing students to overcome their lack of knowledge, skills, and attitude in the preparedness, mitigation, and disaster responses (Jose \& Dufrene, 2014). Furthermore, knowledge and disaster preparedness can be improved through continuous training and disaster drills (Alim et al., 2015). TTE stresses the effectiveness of teamwork which allows the process of obtaining knowledge and determining the right attitude, at each training session, that can be directly applied when carrying out a disaster drill. The simulation-based training such as TTE can be a valuable training modality with the opportunities to exercise and arrange the high-risk events, such as disaster (Gardner et al., 2016). Additionally, it is required to have regular training and education to health workers in disaster response in order to give an adequate clinical knowledge, experience, and skills (Husna, Hatthakit, \& Chaowalit, 2011a).

Furthermore, this study showed that the mean score of students' attitudes increases significantly rather than students' knowledge. The real experience of conducting TTE has significantly enhanced students' attitudes. This could be explained that TTE activities have demonstrated to alter attitudes and interpretations of the nursing students in preparing for disaster drills. By conducting TTE, the students obtained the first enthusiastic experience, directly learn actual disaster scenarios, and they were trained in awareness and readiness to disasters. The students also learned cohesiveness and teamwork in carrying out their respective roles. This assumption is supported by Jose and Dufrene (2014), stating that the simulation has been proven to increase confidence in the workplace areas, as well as the ability to handle emergency situations either in hospital or community settings.

TTE, a pre-disaster drill learning method, aims to improve the knowledge and attitude of the nursing students in disaster preparedness and responses. Nurses as leading professionals are required to perform their roles in disasters. In disaster management, nurses have a major role (Zarea, Beiranvand, Sheini-Jaberi, \& Nikbakht-Nasrabadi, 2014). However, there has been no special action to plan a nursing protocol to face disasters, resulting in an inefficient performance in handling the disaster survivors. Therefore, the knowledge and attitudes related to disaster responses are important in disaster management, especially for nursing students (Zarea et al., 2014). It is more urgent, especially when it comes to Aceh province, Indonesia, which is very vulnerable and in the high-intensity region of disasters. The 2004 earthquake and tsunami disasters had claimed the loss of many lives, injuries, and other devastations impacted 11 countries (World Health Organization, 2005). The dreadful devastating experience from the 
past disaster events should be prevented in the future, and anticipated by all stakeholders, especially through the optimization of disaster nursing curriculum.

Nursing education institutions playing an important role in disaster should well prepare the students for disasters' mitigation, response, recovery, and evaluation phases. It is in accordance with the opinions that nursing education institutions must be able to prepare future nurses to be more effective in responding to all types of disasters through a disaster curriculum (Alfred et al., 2015). Additionally, the curriculum should provide a general and adequate description of the effective and applicable disaster nursing concepts. In the same light, the use of TTE might develop students' clinical competencies and decision making. Disaster simulation allows the students to practice their knowledge and learned materials. The increasing frequency of disasters throughout the world urges the development of innovative disaster learning methods in the education system (Alfred et al., 2015; Curriea, Kourouchea, Gordona, \& Jormb, 2018). The Indonesian nurses' education curriculum system claims that the disaster curriculum is integrated into the disaster nursing subject with three credit points (two credits for in-class learning and credit for practical skills) (Haryanti, Kamil, Ibrahim, \& Hadi, 2016). By studying this course, the students are expected to understand the concept of disaster, the roles and duties of nurses in each disaster management phase. Furthermore, the implementation of this course in the faculty of nursing was preceded by a comprehensive overview of disaster concepts only before moving to laboratory and tabletop exercise skills.

Educational institutions can utilize TTE to provide learning opportunities for students through an emergency plan trial for disaster response. In TTE, there are roles and responsibilities to identify disaster mitigation and preparedness. The team is given a scenario to play a role in disaster mitigation and response. Engaging students in critical thinking and allowing them to practice in a safe environment is crucial for the education process (Farra, Miller, \& Hodgson, 2015). Moreover, school-based disaster management through TTE may effectively reflect disaster management conditions in real emergency situations (Wang, 2016). TTE is considered to be very effective in playing the roles and responsibilities of each team member in disaster management, thus increasing students' ability to respond to disasters. Therefore, students can be more competent in disaster management (Nilsson et al., 2016). Moreover, TTE is a low-cost disaster simulation method but has a high impact on increasing the capacity and competence of health teams for disaster management. This method improves the students' knowledge and attitude towards emergency preparedness and response (Lauren et al., 2018).

The development of knowledge and attitude towards disaster preparedness and response is important to be conducted by educational institutions as a part of the knowledge management system. Knowledge management systems in the disaster emergency management education have become an important priority at this time because the catastrophic events can indiscriminately devastate all humans worldwide (Dorasamy, Murali, \& Kaliannan, 2017). TTE is useful in determining the important role of team members in improving the speed and quality of responses in disaster drills. The education and professional experience from disaster response team members can be obtained through TTE. The professional value of the emergency response team in a disaster can be demonstrated from the ability to perform an effective and efficient disaster response (Woodard, Brenda, David, \& Colleen, 2010). 
Finally, the limited respondents in this study need to be enlarged for the future study. The study also used one group without comparing groups, due to particular reasons such as a limited sample, time, and schedule for TTE simulation that had already been arranged by faculty management. However, in order to minimize the bias, the students involved in this study were assured that they had never received or been involved in any TTE materials or simulations as the exclusion criteria in this study.

\section{CONCLUSION}

This finding reported that TTE significantly improved nursing students' knowledge and attitudes in preparing disaster drill. TTE improved the attitude more than the knowledge of the nursing students through the acquisition of real experiences that were attractive and enthusiastic during TTE simulations. Therefore, this learning method could be implemented and developed in educational institutions by integrating it into the disaster nursing curriculum, generating TTE-based disaster drill practices to improve students' competencies. Further studies should also consider to enlarge the sample size and use control groups as a comparison.

\section{ACKNOWLEDGEMENT}

The authors gratefully thank the students of the Faculty of Nursing for their willingness and kind participation in the study. Also, sincere gratitude to the Dean and the faculty members for their all kinds of assistance.

\section{CONFLICT OF INTEREST}

The authors declare that no conflicts of interest in the study.

\section{REFERENCES}

Alfred, D., Chilton, J., Connor, D., Deal, B., Fountain, R., Hensarling, J., \& Klotz, L. (2015). Preparing for disasters: Education and management strategies explored. Nurse Education in Practice, 15(1), 82-89. doi:10.1016/j.nepr.2014.08.001

Alim, S., Kawabata, M., \& Nakazawa, M. (2015). Evaluation of disaster preparedness training and disaster drill for nursing students. Nurse Education Today, 35(1), 25-31. doi:10.1016/j.nedt.2014.04.016

Althobaity, A., Plummer, V., \& Williams, B. (2017). What are the most common domains of the core competencies of disaster nursing ? A scoping review. International Emergency Nursing, 31, 64-71. doi:10.1016/j.ienj.2016.10.003

Araz, O. M., \& Jehn, M. (2013). Improving public health emergency preparedness through enhanced decision-making environments: A simulation and survey based evaluation. Technological Forecasting \& Social Change, 80(9), 1775-1781. doi:10.1016/j.techfore.2012.09.018

Sandström, B. E., Eriksson, H., Norlander, L., Thorstensson, M., \& Cassel, G. (2014). Training of public health personnel in handling CBRN emergencies: A table-top exercise card concept. Environment International, 72, 164-169.

Bulloch, M. N., Pharm, D., Pinner, N. A., Pharm, D., \& Eure, S. (2013). The impact of a handson exercise on confidence and knowledge regarding preparation of medications used during medical emergencies. Currents in Pharmacy Teaching \& Learning, 5(1), 600-610.

Chee, J. (2014). Clinical simulation using deliberate practice in nursing education: A Wilsonian concept analysis. Nurse Education in Practice, 14(1), 247-252. 
Curriea, J., Kourouchea, S., Gordona, C., Jormb, C. W. (2018). Mass casualty education for undergraduate nursing students in Australia. Nurse Education in Practice, 28(1), 156-162.

Dorasamy, M., Murali, R., \& Kaliannan, M. (2017). Integrated community emergency management and awareness system: A knowledge management system for disaster support. Technological Forecasting \& Social Change. 121(1), 139-167.

Farra, S. L., Miller, E. T., \& Hodgson, E. (2015). Virtual Reality Disaster Training: Translation to Practice. Nurse Education in Practice, 15(1), 53-57.

Gardner, A. K., DeMoya, M. A., Tinkoff, G. H., Brown, K. M., Garcia, G. D., Miller, G. T., ... \& Sachdeva, A. K. (2016). Using simulation for disaster preparedness. Surgery, 160(3), 565-570. doi:10.1016/j.surg.2016.03.027

Haryanti, F., Kamil, H., Ibrahim, K., \& Hadi, M. (2016). Kurikulum Inti Pendidikan Ners Indonesia 2015 [Indonesian Nurse Education Core Curriculum 2015]. Retrieved from https://www.google.com/search?safe=strict\&ei=7dVEX6zeBZ-_3LUPpYKn-

AU\&q=Kurikulum+Inti+Pendidikan+Ners+Indonesia+2015\%2FIndonesian+Nurse+Edu cation+Core+Curriculum+2015.\&oq=Kurikulum+Inti+Pendidikan+Ners+Indonesia +20 $15 \% 2$ FIndonesian+Nurse+Education+Core+Curriculum

Husna, C., Hatthakit, U., \& Chaowalit, A. (2011a). Do knowledge and clinical experience have specific roles in perceived clinical skills for tsunami care among nurses in Banda Aceh, Indonesia?. Australasian Emergency Nursing Journal, 14(2), 95-102. doi:10.1016/j.aenj.2010.12.001

Husna, C., Hatthakit, U., \& Chaowalit, A. (2011b). Emergency training, education and perceived clinical skills for tsunami care among nurses in Banda Aceh, Indonesia. Nurse Media: Journal of Nursing, 1(1), 75-86. doi:10.14710/nmjn.v1i1.748

Husna, C., Kamil, H., Yahya, M., \& Tahlil, T. (2020). An intervention program to improve nurses' competencies in disaster response: A mixed-methods study protocol. Belitung Nursing Journal, 6(3), 85-90.

Husna, C., Tahlil, T., Kamil, H., \& Hayaturrahmi, R. (2018). Preparedness emergency management system among nurses on disaster in Banda Aceh. Proceeding of the 8th AIC: Health and Life Sciences 2018, (24), 103-114.

Jose, M. M., \& Dufrene, C. (2014). Educational competencies and technologies for disaster preparedness in undergraduate nursing education: An integrative review. Nurse Education Today, 34(1), 543-551. doi:10.1016/j.nedt.2013.07.021

Lauren, W., Shane, K., Alex, S., Michael, D., James, O., \& Eric, G. (2018). Disaster training in 24 hours: Evaluation of a novel medical student curriculum in disaster medicine. Journal of Emergency Medicine, 54(3), 348-353. doi:10.1016/j.jemermed.2017.12.008

Leikin, S., Aitchison, P., Pettineo, M., Kharasch, M., \& Wang, E. E. (2011). Simulation applications in emergency medical services. Disease-a-month, 57(11), 723-733. doi:10.1016/j.disamonth.2011.08.012

Nadian, N., Nik, N., Sipon, S., \& Rahim, A. (2015). The factors that influence the transfer of training in disaster preparedness training: A review. Procedia - Social and Behavioral Sciences, 192, 54-58. doi:10.1016/j.sbspro.2015.06.008

National Board for Disaster Management. (2014). Rencana nasional penanggulangan bencana 2015-2019[National disaster management plan 2015-2019]. Jakarta: National Board for Disaster Management.

Nilsson, J., Johansson, E., Carlsson, M., Leksell, J., Lepp, M., Lindholm, C., ..., \& Gardulf, A. (2016). Disaster nursing: Self-reported competence of nursing students and registered nurses, with focus on their readiness to manage violence, serious events and disasters. 
Nurse Education in Practice, 17(1), 102-108.

Park, H. Y., \& Kim, J. S. (2017). Factors influencing disaster nursing core competencies of emergency nurses. Applied Nursing Research, 37(Supplement C), 1-5. doi:10.1016/j.apnr.2017.06.004

Police University Wisconsin. (2012). What is a tabletop exercise?. Retrieved from https://uwpd.wisc.edu/content/uploads/2014/01/What_is_a_tabletop_exercise.pdf

Su, T., Han, X., Chen, F., Du, Y., Zhang, H., Yin, J., ..., \& Cao, G. (2013). Knowledge levels and training needs of disaster medicine among health professionals, medical students, and local residents in Shanghai, China. PLoS ONE, 8(6), e67041. doi:10.1371/journal.pone.0067041

Wang, J. J. (2016). Study on the context of school-based disaster management. International Journal of Disaster Risk Reduction, 19(1), 224-234.

Watson, K. E., Waddell, J. J., \& McCourt, E. M. (inpress). "Vital in today's time": Evaluation of a disaster table-top exercise for pharmacists and pharmacy staff. Research in Social and Administrative Pharmacy. doi:10.1016/j.sapharm.2020.07.009

Woodard, J., Brenda, B., David, W., \& Colleen, T. (2010). Call to action: Integrating student pharmacists, faculty, and pharmacy practitioners into emergency preparedness and response. Journal of the American Pharmacists Association, 50(2), 158-164.

World Health Organization. (2005). Epidemic-prone disease surveillance and response after the tsunami in Aceh Province, Indonesia. Weekly Epidemiological Record, 90(18), 160164.

Yi, P., George, S. K., Paul, J. A., \& Lin, L. (2010). Socio-economic planning sciences hospital capacity planning for disaster emergency management. Socio-Economic Planning Sciences, 44(3), 151-160. doi:10.1016/j.seps.2009.11.002

Zarea, K., Beiranvand, S., Sheini-Jaberi, P., \& Nikbakht-Nasrabadi, A. (2014). Disaster nursing in Iran: Challenges and opportunities. Australasian Emergency Nursing Journal, 17(4), 190-196. doi:10.1016/j.aenj.2014.05.006 